Check for updates

Cite this: New J. Chem., 2017, 41,14259

Received 12th June 2017 Accepted 20th October 2017

DOI: 10.1039/c7nj02102j

rsc.li/njc

\section{Determination of molar refractions and Abraham descriptors for tris(acetylacetonato)chromium(III), tris(acetylacetonato)iron(III) and tris(acetylacetonato)cobalt(III) $\dagger$}

\author{
Michael H. Abraham, (D)*a William E. Acree Jr., ${ }^{b}$ Anthony F. Fucaloroc and \\ Andrew W. Zanella*c
}

\begin{abstract}
We have determined molar refractions of tris(acetylacetonato)chromium(III), tris(acetylacetonato)iron(II) and tris(acetylacetonato)cobalt(III). Although the d-electron structures of the three metal centres differ significantly, the three molar refractions are actually quite close to each other. We then used these molar refractions to determine the Abraham E-descriptor, we calculated the $V$-descriptor by McGowan's method, and then used literature data on solubilities and water-solvent partitions to obtain the rest of the set of descriptors for the three tris(acetylacetonato) complexes. If we take $E$ as the average of those for the chromium, iron and cobalt complexes, we can use limited literature data to obtain the full set of Abraham descriptors for the tris(acetylacetonates) of vanadium(III), yttrium(III), samarium(III), lanthanum(III) and neodymium(III). For the eight complexes, the descriptors vary regularly with complex molecular weight. These show that the complexes are quite polarizable, have zero hydrogen-bond acidity and significant hydrogen bond basicity. From the sets of Abraham descriptors, a very large number of physicochemical properties can be predicted for the eight acetonylacetonates.
\end{abstract}

\section{Introduction}

Methods are now available for the calculation or prediction of numerous physico-chemical properties of organic compounds. Water-octanol partition coefficients can easily be calculated through programs such as BioLoom, ${ }^{1}$ the EPI Suite TM, ${ }^{2}$ ACD ChemSketch, ${ }^{3}$ the ACD Absolv suite ${ }^{4}$ and SPARC. ${ }^{5}$ Some of these programs $^{2,5}$ can be used to calculate numerous other physicochemical properties. However, extension to compounds other than organic compounds is either very limited or non-existent. We have developed a system of properties or 'descriptors' of solute molecules, known as Abraham descriptors or Absolv descriptors. ${ }^{6-13}$ These descriptors, together with a large set of equations we have constructed enables predictions to be made of all sorts of physicochemical, environmental and biological properties. Initially the system was applied to organic compounds and to a few simple inorganic compounds, but we have since applied it to organometallic compounds such mercury compounds ${ }^{14}$

\footnotetext{
${ }^{a}$ Department of Chemistry, University College London, 20 Gordon St, London WC1H OAJ, UK. E-mail: m.h.abraham@ucl.ac.uk

${ }^{b}$ Department of Chemistry, 1155 Union Circle Drive \#305070, University of North Texas, Denton, TX 76203-5017, USA. E-mail: bill.acree@unt.edu

${ }^{c}$ W. M. Keck Science Department, Claremont McKenna, Pitzer, and Scripps Colleges, 925 N. Mills Ave., Claremont, CA 91711, USA.

E-mail: afucaloro@kecksci.claremont.edu, azanella@kecksci.claremont.edu

$\dagger 10.1039 / \mathrm{c} 7 \mathrm{nj} 02102 \mathrm{j}$
}

and the tetraphenyl derivatives of silicon, germanium, tin and lead. ${ }^{15}$ Recently we showed that the system could include derivatives of ferrocene. ${ }^{16}$ This suggests that we might be able to include inorganic complexes into our system. If so, this would mark a very significant extension of predictive methods into the vast area of inorganic complex chemistry. We start with the tris(acetylacetonato) complexes of chromium(III), cobalt(III) and iron(III) because there was a reasonable amount of data on the solubilities of these complexes that we could use. We refer to the complexes as $\mathrm{Cr}(\mathrm{acac})_{3}, \mathrm{Co}(\mathrm{acac})_{3}$ and $\mathrm{Fe}(\mathrm{acac})_{3}$. One of the descriptors we need can be obtained from the refractive index or molar refractivity of a compound. No such data were available for the three tris(acetylacetonato) complexes, and so we decided to determine their molar refractions experimentally.

\section{Experimental}

\section{Compounds}

The three tris(acetylacetonato) complexes, were purchased from Sigma-Aldrich. The purity of the iron compound was $\geq 99.9 \%$, while that of the chromium and cobalt was $99.99 \%$.

\section{Solutions}

For each series of measurements, the pure solvent and ten solutions of the metal compound in 200 proof ethyl alcohol, ACS/USP grade, were used. The solutions ranged from $20 \mathrm{mg}$ of 
compound in $45 \mathrm{~mL}$ of solvent up to $200 \mathrm{mg}$, in $20 \mathrm{mg}$ increments. The iron compound, a fine powder, dissolved readily and yielded a highly colored red solution. The chromium and cobalt compounds, in crystalline form, required sonication to completely dissolve the higher concentration solutions to give violet and green solutions, respectively.

\section{Measurements}

Density and refractive index were measured at $20.00 \pm 0.01{ }^{\circ} \mathrm{C}$ with an Anton Paar DMA 4500 density meter mated to an Anton Paar RXA 170 refractometer through plastic tubing. The techniques, calibration, accuracy, and precision are given elsewhere. ${ }^{17}$ The ranges for the density and refractive index are 0.79101 to $0.79639 \mathrm{~kg} \mathrm{~L}^{-1}$ and 1.36135 to 1.36290 , respectively. These ranges fall well within the manufacturer's recommendations for the calibration methods used here. The system was calibrated before each series of measurements with deionized water at $20{ }^{\circ} \mathrm{C}$. For each case a value of $0.99821 \mathrm{~g} \mathrm{~mL}^{-1}$ were measured and agree with the accepted value for water at $20{ }^{\circ} \mathrm{C}$ of $0.998206 \mathrm{~g} \mathrm{~mL}^{-1}$ (one additional significant figure).

\section{Data treatment}

Table 1 reports the mole fractions, densities, and refractive index values for the ethanolic solutions of the complexes.

Table $1 x_{2}, \rho\left(\mathrm{g} \mathrm{cm}^{-3}\right), n, V^{M}\left(\mathrm{~cm}^{3} \mathrm{~mol}^{-1}\right)$, and $R\left(\mathrm{~cm}^{3} \mathrm{~mol}^{-1}\right)$ for ethanolic solutions of $\mathrm{M}(\mathrm{acac})_{3}[\mathrm{M}=\mathrm{Cr}$, Fe, and $\mathrm{Co}]$

\begin{tabular}{lllll}
\hline$x_{2}$ & $\rho$ & $n$ & $V^{\mathrm{M}}$ & $R$ \\
\hline $\mathrm{M}=\mathrm{Cr}$ & & & & \\
$7.63 \times 10^{-5}$ & 0.79119 & 1.36145 & 58.25799 & 12.90393 \\
0.000152 & 0.79137 & 1.36154 & 58.27361 & 12.91027 \\
0.000223 & 0.79151 & 1.36163 & 58.29077 & 12.91696 \\
0.000299 & 0.79167 & 1.36171 & 58.30788 & 12.92332 \\
0.0003755 & 0.79193 & 1.36180 & 58.31811 & 12.92847 \\
0.0004413 & 0.79205 & 1.36187 & 58.33449 & 12.93435 \\
0.0005191 & 0.79220 & 1.36197 & 58.35320 & 12.94171 \\
0.0005937 & 0.79239 & 1.36206 & 58.36778 & 12.94783 \\
0.0006703 & 0.79253 & 1.36214 & 58.38679 & 12.95461 \\
0.0007446 & 0.79271 & 1.36222 & 58.40192 & 12.96054 \\
& & & & \\
$\mathrm{M}=\mathrm{Fe}$ & & & & \\
$7.46 \times 10^{-5}$ & 0.79119 & 1.36154 & 58.25771 & 12.90675 \\
0.000153 & 0.79136 & 1.36163 & 58.27570 & 12.91362 \\
0.000222 & 0.79153 & 1.36173 & 58.29005 & 12.92001 \\
0.000294 & 0.79170 & 1.36182 & 58.30533 & 12.92628 \\
0.000370 & 0.79187 & 1.36192 & 58.32239 & 12.93327 \\
0.0004486 & 0.79202 & 1.36202 & 58.34165 & 12.94075 \\
0.0005131 & 0.79220 & 1.36211 & 58.35342 & 12.94625 \\
0.0005826 & 0.79236 & 1.36219 & 58.36858 & 12.95218 \\
0.0006546 & 0.79254 & 1.36229 & 58.38320 & 12.95863 \\
0.0007446 & 0.79272 & 1.36238 & 58.40482 & 12.96632 \\
& & & & \\
$\mathrm{M}=\mathrm{Co}$ & & & & \\
$7.386 \times 10^{-5}$ & 0.79116 & 1.36144 & 58.25991 & 12.90403 \\
0.000142 & 0.79142 & 1.36154 & 58.26738 & 12.90889 \\
0.000219 & 0.79168 & 1.36165 & 58.27835 & 12.91485 \\
0.000296 & 0.79188 & 1.36175 & 58.29407 & 12.92154 \\
0.000364 & 0.79201 & 1.36184 & 58.31115 & 12.92821 \\
0.0004389 & 0.79213 & 1.36194 & 58.33153 & 12.93594 \\
0.0005135 & 0.79231 & 1.36203 & 58.34747 & 12.94236 \\
0.0005862 & 0.79252 & 1.36213 & 58.36045 & 12.94845 \\
0.0006493 & 0.79265 & 1.36221 & 58.37558 & 12.95437 \\
0.0007486 & 0.79290 & 1.36233 & 58.39603 & 12.96276
\end{tabular}

The molar volumes, $V^{\mathrm{M}}$, for each solution were calculated from

$$
V^{\mathrm{M}}=\frac{x_{1} M_{1}+x_{2} M_{2}}{\rho}
$$

where $x_{i}$ and $M_{i}$ are the mole fractions and molar masses of the solutions' components, respectively, and where $i=1,2$ refer to the solvent and solute, respectively. The molar refractions of the solutions, $R$, were calculated from the molar volumes and refractive indexes $(n)$ according to

$$
R=\left(\frac{n^{2}-1}{n^{2}+2}\right) V^{M}
$$

The $V^{\mathrm{M}}$ and $R$-values for each solution are also given in Table 1. Since $V^{\mathrm{M}}$ is a homogeneous function of $n_{1}$ and $n_{2}$, following Euler, one gets

$$
V^{\mathrm{M}}=x_{1} V_{1}^{\mathrm{M}}+x_{2} V_{2}^{\mathrm{M}}=V_{1}^{\mathrm{M}}+x_{2}\left(V_{2}^{\mathrm{M}}-V_{1}^{\mathrm{M}}\right),
$$

where $V_{1}^{\mathrm{M}}$ and $V_{2}^{\mathrm{M}}$ are the partial molar volumes for the solvent and solute, respectively. An analogous equation obtains for molar refraction $(R) .{ }^{18}$ All $V^{\mathrm{M}}$ and $R$-values exhibit nearly linear dependence on the mole fraction of solute. Consequently, intercepts and slopes were calculated employing Excel's linear regression routine, and standard deviations were determined from Excel's ANOVA routine. The refractive index $\left(n_{2}\right)$ for each complex was calculated according to

$$
R_{2}=\left(\frac{n_{2}^{2}-1}{n_{2}^{2}+2}\right) V_{2}^{M}
$$

\section{Descriptor methodology}

Our method for the determination of descriptors for neutral solutes uses two linear free energy relationships, eqn (5) and (6).

$$
\begin{aligned}
& \log \mathrm{SP}=c+e E+s S+a A+b B+v V \\
& \log \mathrm{SP}=c+e E+s S+a A+b B+l L
\end{aligned}
$$

Eqn (5) is used when the dependent variable, log SP, refers to condensed phase processes, such as the water-solvent partition coefficient for a series of solutes in a given system; then SP itself is the water-solvent partition coefficient. Eqn (6) is used when $\log$ SP refers to a gas to system partition, where SP is the gas to system partition coefficient.

The independent variables in eqn (5) and (6) are solute descriptors as follows: ${ }^{6-13} E$ is the solute excess molar refractivity in units of $\left(\mathrm{cm}^{3} \mathrm{~mol}^{-1}\right) / 10, S$ is the solute dipolarity/polarizability, $A$ and $B$ are the overall or summation hydrogen bond acidity and basicity, $V$ is the McGowan characteristic volume in units of $\left(\mathrm{cm}^{3} \mathrm{~mol}^{-1}\right) / 100$ and $L$ is the logarithm of the gas-hexadecane partition coefficient, at $298 \mathrm{~K}$. The coefficients in eqn (5) and (6) are obtained by multiple linear regression analysis, and serve to characterize the system under consideration.

In order to apply eqn (5) or (6), values of the dependent variable are needed. The most direct source is a directly determined water-solvent partition coefficient, $P$, as $\log P$. However, most of the relevant data consists of solubilities in (dry) solvents and in water. Then partition coefficients can be 
obtained indirectly through eqn (7), where $C_{\mathrm{w}}$ and $C_{\mathrm{s}}$ are solubilities in mol dm ${ }^{-3}$, in water and a given solvent. If a value of $C_{\mathrm{w}}$ is not known, or is perhaps doubtful, then $\log C_{\mathrm{w}}$ can be allowed to float, and becomes another unknown parameter to deduce.

$$
\log P=\log C_{\mathrm{s}}-\log C_{\mathrm{w}}
$$

We can greatly increase the number of simultaneous equations, by converting every $\log P$ value from eqn (7) into a corresponding $\log K_{\mathrm{s}}$ value through eqn (8), where $K_{\mathrm{s}}$ is the gas to solvent partition coefficient and $K_{\mathrm{w}}$ is the gas to water partition coefficient. Now $\log K_{\mathrm{w}}$ itself is another variable to be determined.

$$
\log P=\log K_{\mathrm{s}}-\log K_{\mathrm{w}}
$$

This leaves $E, S, A, B, V, L$, and possibly $\log C_{\mathrm{w}}$ and $\log K_{\mathrm{w}}$ to be determined through a set of simultaneous equations with $\log P$ and $\log K_{\mathrm{s}}$ as the dependent variables in eqn (5) and (6). The Microsoft 'Solver' add-on is particularly useful, and any number of simultaneous equations can be solved to give a 'best-fit' solution.

Since we have as many as eight variables to obtain, it is useful to be able to deduce one or more variables independently, and so reduce the number that have to be obtained through the set of simultaneous equations. For organic compounds, $E$ can be calculated through two programs ${ }^{4,19}$ and can also be obtained from a calculated liquid refractive index at $293 \mathrm{~K} .{ }^{3}$ Now that we have experimental molar refractions there is no problem in obtaining values of $E$.

The volume descriptor, $V$, can very easily be calculated for organic compounds through McGowan's method, ${ }^{20}$ but as we showed in the case of ferrocene, it is not straightforward to use McGowan's method for inorganic complexes.

The McGowan volume, $V_{\mathrm{x}}=100 \times V$, is calculated from atomic increments, as shown in Table $2,{ }^{16,20,21}$ with 6.56 subtracted for each bond (single, double and triple bonds all counting as one bond). If the structure of an acac derivative of cobalt(III) is as shown in Fig. 1, then for tris(acetylacetonato)Co(III) there are $15 \times 3=45$ bonds. Then with $V_{\mathrm{x}}$ for $\mathrm{Co}(3+)=0.78 \mathrm{~mL} \mathrm{~mol}^{-1}$, for the complex we have $V_{\mathrm{x}}=21 \times 8.71+15 \times 16.35+6 \times 12.43+0.78-6.56 \times 45=$ $208.3 \mathrm{~cm}^{3} \mathrm{~mol}^{-1}$. However, the $\mathrm{C}=\mathrm{O} \rightarrow \mathrm{Co}$ coordinate bond is not a 'McGowan' bond, and the oxygen atom in $=\mathrm{O} \rightarrow$ has three bonds instead of two. So there is a difficulty in calculating the McGowan volume for the cyclic structure.

Suppose we use the non-cyclic structure, Fig. 2. Now the number of bonds is $14 \times 3=42$, and $V_{\mathrm{x}}=21 \times 8.71+15 \times$ $16.35+6 \times 12.43+0.78-6.56 \times 42=228.0 \mathrm{~cm}^{3} \mathrm{~mol}^{-1}$, substantially larger than that calculated for the cyclic structure.

We can resolve this by using the equations we have constructed ${ }^{16}$ for the correlation of $V_{\mathrm{x}}$ against the partial molal volumes,

Table 2 Atomic volumes, $V_{x}$, in $\mathrm{cm}^{3} \mathrm{~mol}^{-116,20,21}$

\begin{tabular}{llllll}
\hline H 8.71 & & & & & \\
C 16.35 & N 14.39 & O 12.43 & F 10.48 & $\mathrm{Fe}^{3+} 0.78$ & $\mathrm{Y}^{3+} 3.58$ \\
Si 26.83 & P 24.87 & S 22.91 & Cl 20.95 & $\mathrm{Co}^{3+} 0.78$ & $\mathrm{Sm}^{3+} 3.66$ \\
Ge 31.02 & As 29.42 & Se 27.81 & Br 26.21 & $\mathrm{Cr}^{3+} 1.08$ & $\mathrm{Nd}^{3+} 3.89$ \\
Sn 39.35 & Sb 37.74 & Te 36.14 & I 34.53 & $\mathrm{V}^{3+} 1.18$ & $\mathrm{La}^{3+} 5.11$
\end{tabular}

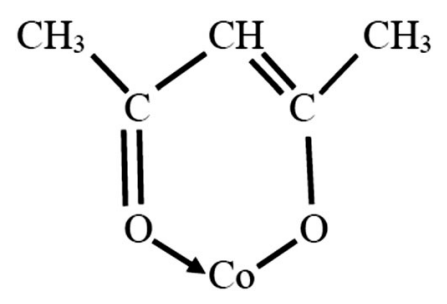

Fig. 1 A possible configuration of $\mathrm{Co}(\mathrm{acac})_{3}$ for the calculation of McGowan's volume, illustrated for just one of the acac molecules.

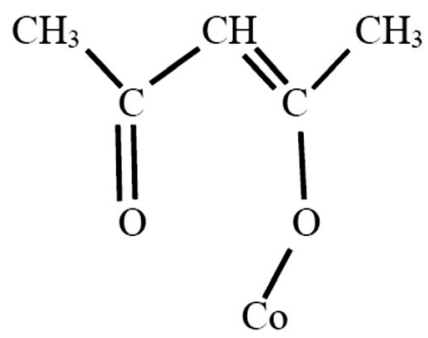

Fig. 2 A possible 'open chain' configuration of $\mathrm{Co}(\mathrm{acac})_{3}$ for the calculation of McGowan's volume.

$V_{2}^{\mathrm{M}}(\mathrm{MeCN})$, of a series of organic and inorganic compounds in acetonitrile solvent, ${ }^{22}$ eqn (5) and (6). For $\mathrm{Co}(\mathrm{acac})_{3}$ we have that $V_{2}^{\mathrm{M}}(\mathrm{MeCN})=256.6 \mathrm{~cm}^{3} \mathrm{~mol}^{-1}$ in acetonitrile, ${ }^{22}$ and so calculated values of $V_{\mathrm{x}}$ are $233.1 \pm 6.2$ on eqn (9) and $228.2 \pm 7.9$ on eqn (10), very close to the McGowan volume of $228.0 \mathrm{~cm}^{3} \mathrm{~mol}^{-1}$ as calculated for the non-cyclic structure in Fig. 2. Similar calculations for $\mathrm{Cr}(\mathrm{acac})_{3}$ and $\mathrm{Fe}(\mathrm{acac})_{3}$ confirm the use of the non-cyclic structure in the calculation of $V_{\mathrm{x}}$. We make it clear that the structure in Fig. 2 is only for the purpose of calculating $V_{\mathrm{x}}$ and is not intended as the representation of the actual structure of $\mathrm{Co}(\mathrm{acac})_{3}$. However, now that we have shown that the structure in Fig. 2 can be used to calculate $V$ for $\mathrm{M}(\mathrm{acac})_{3}$ complexes, we can use the same method to calculate $V$ for complexes of various substituted acetylacetones.

$$
\begin{gathered}
V_{\mathrm{x}}=-10.237+0.9482 V_{2}^{\mathrm{M}}(\mathrm{MeCN}) \quad N=58, \mathrm{SD}=6.05, R^{2}=0.993 \\
F=7531.6, \text { PRESS }=2181.40, Q^{2}=0.992, \mathrm{PSD}=6.24 \\
V_{\mathrm{x}}=0.8895 V_{2}^{\mathrm{M}}(\mathrm{MeCN}) \quad N=58, \mathrm{SD}=7.74 \\
\text { PRESS }=3534.0, \mathrm{PSD}=7.87
\end{gathered}
$$

\section{Results and discussion}

\section{Molar refractions}

The molar volumes, molar refractions, and refractive indices are listed in Table 3. The molar volumes of the three tris-acac metal compounds follow the trend of $\mathrm{Co}<\mathrm{Fe} \approx \mathrm{Cr}$, which inversely follows the molecular masses of the three compounds. This observation is in accord with the results of crystal structures $^{23-25}$ of the compounds in which the metal oxygen bond distances increase in roughly the same direction: Co

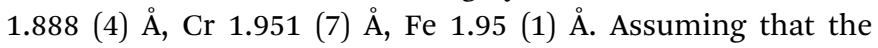
other bond $(\mathrm{C}-\mathrm{H}, \mathrm{C}-\mathrm{C}$, and $\mathrm{C}-\mathrm{O})$ distances within the acac 
Table $3 \quad V_{2}^{M}, R_{2}$, and $n_{2}$ for $M(\text { acac })_{3}$ complexes $^{a}$

\begin{tabular}{lccl}
\hline $\mathrm{M}$ & $V_{2}^{\mathrm{M}}, \mathrm{cm}^{3} \mathrm{~mol}^{-1}$ & $R_{2}, \mathrm{~cm}^{3} \mathrm{~mol}^{-1}$ & $n_{2}$ \\
\hline $\mathrm{Cr}$ & $272.9(2.9)$ & $97.6(0.7)$ & 1.6338 \\
$\mathrm{Fe}$ & $276.3(1.4)$ & $102.3(0.4)$ & 1.6638 \\
$\mathrm{Co}$ & $269.3(5.9)$ & $101.9(1.1)$ & 1.6809 \\
\multicolumn{2}{l}{${ }^{a}$ Standard deviations in parentheses. } &
\end{tabular}

ligand itself do not vary appreciably, then the cobalt compound would be expected to have the smallest volume.

The d-electron structures of the three metal centers also differ significantly with the chromium(III) and iron(III) centers being paramagnetic high-spin $\mathrm{d}^{3}$ and $\mathrm{d}^{5}$, respectively, while the cobalt(III) center is diamagnetic low-spin $\mathrm{d}^{6}$.

\section{Descriptors}

Water-solvent partition coefficients into water-methanol mixtures, dimethylsulfoxide (DMSO) and dioxane for $\mathrm{Cr}(\mathrm{acac})_{3}$ have been listed by Alousy and Burgess. ${ }^{26}$ Watarai et al. ${ }^{27}$ have determined partitions into dodecane, tetrachloromethane and benzene. Solubilities of $\mathrm{Cr}(\mathrm{acac})_{3}$ are known in water-ethanol mixtures ${ }^{28}$ but only in those of low ethanol content, and we did not use any of these values. Solubilities are also known in the solvents dimethylformamide ${ }^{29,30}$ dichloromethane, 1,1,1-trichloroethane and tetrahydrofuran. ${ }^{30}$ The solubility of $\mathrm{Cr}(\mathrm{acac})_{3}$ in water at $298 \mathrm{~K}$ is given as $\log C_{\mathrm{w}}=-2.55,{ }^{29}$ with $C_{\mathrm{w}}$ in $\mathrm{mol} \mathrm{dm}^{-3}$, and so the various solubilities can be converted into values of $\log P$ through eqn (7). Then if we take $\log K_{\mathrm{w}}$ as unknown to be determined, we can convert all the $\log P$ values into $\log K_{\mathrm{s}}$ values through eqn (8). We can calculate $V_{\mathrm{x}}=2.2830$ by McGowan's method, and from the refractive index in Table 3 calculate that $E=2.222$. This leaves the descriptors $S, A, B, L$ and $\log K_{\mathrm{w}}$ to be obtained from a set of simultaneous equations in $\log P$. In Table 4 are the values of $\log P$ that we used. A preliminary analysis showed that three values were out of line, leaving 14 values of $\log P$ and 14 values of the corresponding $\log K_{\mathrm{s}}$. We also had two equations in $\log K_{\mathrm{w}}$ giving a total of 30 simultaneous

Table 4 Calculated and observed values of water-solvent partition coefficients, as $\log P$, for $\mathrm{Cr}(\mathrm{acac})_{3}$

\begin{tabular}{llcll}
\hline Solvent & $\log P($ calc $)$ & $\log P$ (obs) & Ref. & \\
\hline Dichloromethane & 2.988 & 2.500 & 30 & Not used \\
Tetrachloromethane & 1.975 & 2.041 & 27 & \\
Dodecane & 0.322 & -0.733 & 27 & Not used \\
Benzene & 2.397 & 2.534 & 27 & \\
Tetrahydrofuran & 1.946 & 1.740 & 30 & Not used \\
Dioxane & 1.865 & 1.870 & 26 & \\
Dimethylfomamide & 1.915 & 1.934 & 30 & \\
Dimethylsulfoxide & 1.627 & 1.610 & 26 & \\
90\% methanol-water & 1.729 & 1.600 & 26 & \\
80\% methanol-water & 1.498 & 1.510 & 26 & \\
70\% methanol-water & 1.288 & 1.350 & 26 & \\
60\% methanol-water & 1.095 & 1.160 & 26 & \\
$50 \%$ methanol-water & 0.902 & 0.860 & 26 & \\
$40 \%$ methanol-water & 0.733 & 0.560 & 26 & \\
30\% methanol-water & 0.536 & 0.330 & 26 & \\
20\% methanol-water & 0.385 & 0.140 & 26 & \\
10\% methanol-water & 0.211 & 0.070 & 26 & \\
& & &
\end{tabular}

equations. The equation coefficients ${ }^{16,31-33}$ for eqn (5) and (6) are collected in Tables 5 and 6 . The best fit solution of the 30 simultaneous equations yielded the descriptors shown in Table 7, and the calculated values of $\log P$ from these descriptors are in Table 4.

The 14 calculated and observed values of $\log P$ for $\operatorname{Cr}(\mathrm{acac})_{3}$ in Table 4 yield an average error AE of 0.042, an average absolute error AAE of 0.094 and a standard deviation of $0.125 \mathrm{log}$ units. For the total of 30 simultaneous equations the SD is $0.123 \mathrm{log}$ units. This is shown in Table 7, where $N$ is the total number of equations used. We left out data in three solvents in Table 4, where the difference between $\log P($ calc $)$ and $\log P(\mathrm{obs})$ was very large.

For $\mathrm{Fe}(\mathrm{acac})_{3}$, water-solvent partition coefficients are known into propan-2-ol, DMSO, and various water-methanol mixtures. ${ }^{26}$ Solubilities have been determined in several solvents ${ }^{30,34}$ but apparently not in water itself. However, we can take $\log C_{\mathrm{w}}$ as another descriptor to be determined through our analysis. We find that with $\log C_{\mathrm{w}}=-2.38$, the observed values of $\log P$ and those

Table 5 Coefficients in eqn (5) for water-solvent partitions as $\log P$

\begin{tabular}{|c|c|c|c|c|c|c|}
\hline \multirow[b]{2}{*}{ Solvent } & \multicolumn{6}{|c|}{ Coefficients } \\
\hline & $c$ & $e$ & $s$ & $a$ & $b$ & $v$ \\
\hline Hexane & 0.333 & 0.560 & -1.710 & -3.578 & -4.939 & 4.463 \\
\hline Heptane & 0.297 & 0.634 & -1.755 & -3.571 & -4.946 & 4.488 \\
\hline Cyclohexane & 0.159 & 0.784 & -1.678 & -3.740 & -4.929 & 4.577 \\
\hline Formamide & -0.171 & 0.070 & 0.308 & 0.589 & -3.152 & 2.432 \\
\hline Dimethylformamide & -0.305 & -0.058 & 0.343 & 0.358 & -4.865 & 4.486 \\
\hline Dimethylacetamide & -0.271 & 0.084 & 0.209 & 0.915 & -5.003 & 4.557 \\
\hline Acetonitrile & 0.413 & 0.077 & 0.326 & -1.566 & -4.391 & 3.364 \\
\hline Nitromethane & 0.023 & -0.091 & 0.793 & -1.463 & -4.364 & 3.460 \\
\hline Dimethylsulfoxide & -0.194 & 0.327 & 0.791 & 1.260 & -4.540 & 3.361 \\
\hline Propylene carbonate & -0.149 & 0.754 & -0.966 & 0.684 & -3.134 & 3.247 \\
\hline Propanone & 0.313 & 0.312 & -0.121 & -0.608 & -4.753 & 3.942 \\
\hline Tetrahydrofuran & 0.223 & 0.363 & -0.384 & -0.238 & -4.932 & 4.450 \\
\hline 1,2-Dichloroethane & 0.183 & 0.294 & -0.134 & -2.801 & -4.291 & 4.180 \\
\hline Benzene & 0.142 & 0.464 & -0.588 & -3.099 & -4.625 & 4.491 \\
\hline Toluene & 0.125 & 0.431 & -0.644 & -3.002 & -4.748 & 4.524 \\
\hline Chlorobenzene & 0.065 & 0.381 & -0.521 & -3.183 & -4.700 & 4.614 \\
\hline Nitrobenzene & -0.152 & 0.525 & 0.081 & -2.332 & -4.494 & 4.187 \\
\hline Ethylene glycol & -0.270 & 0.578 & -0.511 & 0.715 & -2.619 & 2.729 \\
\hline 2-Ethoxyethanol & 0.133 & 0.392 & -0.419 & 0.125 & -4.200 & 3.888 \\
\hline 2-Butoxyethanol & -0.055 & 0.377 & -0.607 & -0.080 & -4.371 & 4.234 \\
\hline Octan-1-ol, wet & 0.088 & 0.562 & -1.054 & 0.034 & -3.460 & 3.814 \\
\hline Ethanol & 0.222 & 0.471 & -1.035 & 0.326 & -3.596 & 3.857 \\
\hline $96 \%$ ethanol & 0.238 & 0.353 & -0.833 & 0.297 & -3.533 & 3.724 \\
\hline $95 \%$ ethanol & 0.239 & 0.328 & -0.795 & 0.294 & -3.514 & 3.697 \\
\hline $90 \%$ ethanol & 0.243 & 0.213 & -0.575 & 0.262 & -3.450 & 3.545 \\
\hline $80 \%$ ethanol & 0.172 & 0.175 & -0.465 & 0.260 & -3.212 & 3.323 \\
\hline $70 \%$ ethanol & 0.063 & 0.085 & -0.368 & 0.311 & -2.936 & 3.102 \\
\hline $60 \%$ ethanol & -0.040 & 0.138 & -0.335 & 0.293 & -2.675 & 2.812 \\
\hline $50 \%$ ethanol & -0.142 & 0.124 & -0.252 & 0.251 & -2.275 & 2.415 \\
\hline $40 \%$ ethanol & -0.221 & 0.131 & -0.159 & 0.171 & -1.809 & 1.918 \\
\hline $30 \%$ ethanol & -0.269 & 0.107 & -0.098 & 0.133 & -1.316 & 1.414 \\
\hline $20 \%$ ethanol & -0.252 & 0.042 & -0.040 & 0.096 & -0.823 & 0.916 \\
\hline $10 \%$ ethanol & -0.173 & -0.023 & -0.001 & 0.065 & -0.372 & 0.454 \\
\hline Methanol & 0.276 & 0.334 & -0.714 & 0.243 & -3.320 & 3.549 \\
\hline $95 \%$ methanol & 0.270 & 0.278 & -0.520 & 0.230 & -3.368 & 3.365 \\
\hline $90 \%$ methanol & 0.258 & 0.250 & -0.452 & 0.229 & -3.206 & 3.175 \\
\hline $80 \%$ methanol & 0.172 & 0.197 & -0.319 & 0.241 & -2.912 & 2.842 \\
\hline $70 \%$ methanol & 0.098 & 0.192 & -0.260 & 0.266 & -2.558 & 2.474 \\
\hline $60 \%$ methanol & 0.053 & 0.207 & -0.238 & 0.272 & -2.157 & 2.073 \\
\hline $50 \%$ methanol & 0.023 & 0.223 & -0.222 & 0.264 & -1.747 & 1.662 \\
\hline $40 \%$ methanol & 0.020 & 0.222 & -0.205 & 0.218 & -1.329 & 1.259 \\
\hline $30 \%$ methanol & 0.016 & 0.187 & -0.172 & 0.165 & -0.953 & 0.898 \\
\hline $20 \%$ methanol & 0.022 & 0.142 & -0.138 & 0.088 & -0.574 & 0.559 \\
\hline $10 \%$ methanol & 0.012 & 0.072 & -0.081 & 0.026 & -0.249 & 0.266 \\
\hline
\end{tabular}


Table 6 Coefficients in eqn (6) for gas-solvent partitions as $\log K$

\begin{tabular}{|c|c|c|c|c|c|c|}
\hline \multirow[b]{2}{*}{ Solvent } & \multicolumn{6}{|c|}{ Coefficients } \\
\hline & $c$ & $e$ & $s$ & $a$ & $b$ & $l$ \\
\hline Hexane & 0.320 & 0.000 & 0.000 & 0.000 & 0.000 & 0.945 \\
\hline Heptane & 0.284 & 0.000 & 0.000 & 0.000 & 0.000 & 0.950 \\
\hline Cyclohexane & 0.163 & -0.110 & 0.000 & 0.000 & 0.000 & 1.013 \\
\hline Formamide & -0.800 & 0.310 & 2.292 & 4.130 & 1.933 & 0.442 \\
\hline Dimethylformamide & -0.391 & -0.869 & 2.107 & 3.774 & 0.000 & 1.011 \\
\hline Dimethylacetamide & -0.308 & -0.736 & 1.802 & 4.361 & 0.000 & 1.028 \\
\hline Acetonitrile & -0.007 & -0.595 & 2.461 & 2.085 & 0.418 & 0.738 \\
\hline Nitromethane & -0.340 & -0.297 & 2.689 & 2.193 & 0.514 & 0.728 \\
\hline Dimethylsulfoxide & -0.556 & -0.223 & 2.903 & 5.037 & 0.000 & 0.719 \\
\hline Propylene carbonate & -0.356 & -0.413 & 2.587 & 2.207 & 0.455 & 0.719 \\
\hline Propanone & 0.127 & -0.387 & 1.733 & 3.060 & 0.000 & 0.866 \\
\hline Tetrahydrofuran & 0.189 & -0.347 & 1.238 & 3.289 & 0.000 & 0.982 \\
\hline 1,2-Dichloroethane & 0.017 & -0.337 & 1.600 & 0.774 & 0.637 & 0.921 \\
\hline Benzene & 0.107 & -0.313 & 1.053 & 0.457 & 0.169 & 1.020 \\
\hline Toluene & 0.085 & -0.400 & 1.063 & 0.501 & 0.154 & 1.011 \\
\hline Chlorobenzene & 0.064 & -0.399 & 1.151 & 0.313 & 0.171 & 1.032 \\
\hline Nitrobenzene & -0.296 & 0.092 & 1.707 & 1.147 & 0.443 & 0.912 \\
\hline 2-Ethoxyethanol & -0.064 & -0.257 & 1.452 & 3.672 & 0.662 & 0.843 \\
\hline 2-Butoxyethanol & -0.109 & -0.304 & 1.126 & 3.407 & 0.660 & 0.914 \\
\hline Octan-1-ol, wet & -0.222 & 0.088 & 0.701 & 3.473 & 1.477 & 0.851 \\
\hline Ethanol & 0.222 & 0.471 & -1.035 & 0.326 & -3.596 & 3.857 \\
\hline $96 \%$ ethanol & 0.238 & 0.353 & -0.833 & 0.297 & -3.533 & 3.724 \\
\hline 95\% ethanol & 0.239 & 0.328 & -0.795 & 0.294 & -3.514 & 3.697 \\
\hline $90 \%$ ethanol & 0.243 & 0.213 & -0.575 & 0.262 & -3.450 & 3.545 \\
\hline $80 \%$ ethanol & 0.172 & 0.175 & -0.465 & 0.260 & -3.212 & 3.323 \\
\hline $70 \%$ ethanol & 0.063 & 0.085 & -0.368 & 0.311 & -2.936 & 3.102 \\
\hline $60 \%$ ethanol & -0.040 & 0.138 & -0.335 & 0.293 & -2.675 & 2.812 \\
\hline $50 \%$ ethanol & -0.142 & 0.124 & -0.252 & 0.251 & -2.275 & 2.415 \\
\hline $40 \%$ ethanol & -0.221 & 0.131 & -0.159 & 0.171 & -1.809 & 1.918 \\
\hline $30 \%$ ethanol & -0.269 & 0.107 & -0.098 & 0.133 & -1.316 & 1.414 \\
\hline $20 \%$ ethanol & -0.252 & 0.042 & -0.040 & 0.096 & -0.823 & 0.916 \\
\hline $10 \%$ ethanol & -0.173 & -0.023 & -0.001 & 0.065 & -0.372 & 0.454 \\
\hline Methanol & 0.276 & 0.334 & -0.714 & 0.243 & -3.320 & 3.549 \\
\hline $95 \%$ methanol & 0.270 & 0.278 & -0.520 & 0.230 & -3.368 & 3.365 \\
\hline $90 \%$ methanol & 0.258 & 0.250 & -0.452 & 0.229 & -3.206 & 3.175 \\
\hline $80 \%$ methanol & 0.172 & 0.197 & -0.319 & 0.241 & -2.912 & 2.842 \\
\hline $70 \%$ methanol & 0.098 & 0.192 & -0.260 & 0.266 & -2.558 & 2.474 \\
\hline $60 \%$ methanol & 0.053 & 0.207 & -0.238 & 0.272 & -2.157 & 2.073 \\
\hline $50 \%$ methanol & 0.023 & 0.223 & -0.222 & 0.264 & -1.747 & 1.662 \\
\hline $40 \%$ methanol & 0.020 & 0.222 & -0.205 & 0.218 & -1.329 & 1.259 \\
\hline $30 \%$ methanol & 0.016 & 0.187 & -0.172 & 0.165 & -0.953 & 0.898 \\
\hline & 0.022 & 0.142 & -0.138 & 0.088 & -0.574 & 0.559 \\
\hline $10 \%$ methanol & 0.012 & 0.072 & -0.081 & 0.026 & -0.249 & 0.266 \\
\hline
\end{tabular}

Table 7 Determined descriptors for the tris(acetylacetonates)

\begin{tabular}{llllllllll}
\hline Complex & $E$ & $S$ & $A$ & $B$ & $V$ & $L$ & $\log K_{\mathrm{w}}$ & $N$ & $\mathrm{SD}$ \\
\hline $\mathrm{Cr}(\mathrm{acac})_{3}$ & 2.222 & 1.67 & 0.00 & 1.74 & 2.2830 & 11.77 & 10.89 & 30 & 0.123 \\
$\mathrm{Fe}(\mathrm{acac})_{3}$ & 2.524 & 2.25 & 0.00 & 1.74 & 2.2800 & 12.34 & 12.38 & 46 & 0.136 \\
$\mathrm{Co}(\mathrm{acac})_{3}$ & 2.694 & 2.21 & 0.00 & 1.91 & 2.2800 & 12.69 & 13.36 & 68 & 0.205 \\
$\mathrm{~V}(\mathrm{acac})_{3}$ & 2.480 & 2.55 & 0.00 & 1.57 & 2.2840 & 12.82 & 12.57 & 6 & 0.013 \\
$\mathrm{Y}(\mathrm{acac})_{3}$ & 2.480 & 2.85 & 0.00 & 1.94 & 2.2834 & 13.26 & 15.13 & 10 & 0.182 \\
$\mathrm{Sm}(\mathrm{acac})_{3}$ & 2.480 & 2.83 & 0.00 & 2.36 & 2.2835 & 13.27 & 17.07 & 12 & 0.196 \\
$\mathrm{La}(\mathrm{acac})_{3}$ & 2.480 & 3.01 & 0.00 & 2.38 & 2.3233 & 13.53 & 17.61 & 10 & 0.190 \\
$\mathrm{Nd}(\mathrm{acac})_{3}$ & 2.480 & 2.98 & 0.00 & 2.37 & 2.3088 & 13.49 & 17.49 & 12 & 0.158
\end{tabular}

calculated from $\log C_{\mathrm{s}}$ through eqn (7) are very consistent. We calculate $V=2.2800$ and from the refractive index that we have determined, Table 2, we calculate $E=2.524$; then the unknowns to be found by solution of the set of simultaneous equations in $\log P$ are $S, A, B, L, \log K_{\mathrm{w}}$ and $\log C_{\mathrm{w}}$. We used a total of 22 values of $\log P$, 22 values of the corresponding $\log K_{\mathrm{s}}$ through eqn (8) and two equations in $\log K_{\mathrm{w}}$ leading to a set of 46 simultaneous equations.
Table 8 Calculated and observed values of water-solvent partition coefficients, as $\log P$, for Fe(acac) 3

\begin{tabular}{lrrlr}
\hline Solvent & $\log P($ calc $)$ & $\log P($ obs $)$ & Ref. & \\
\hline Hexane & -0.519 & -0.367 & 34 & \\
Heptane & -0.425 & -0.430 & 34 & \\
Cyclohexane & 0.221 & -0.005 & 34 & Not used \\
Dichloromethane & 2.898 & 2.313 & 30 & Not used \\
Tetrachloromethane & 1.447 & 1.900 & 34 & \\
Benzene & 2.182 & 2.263 & 34 & \\
Toluene & 1.817 & 1.923 & 34 & \\
Chlorobenzene & 2.196 & 2.309 & 34 & \\
Tetrahydrofuran & 1.818 & 1.858 & 30 & \\
Dimethylformamide & 2.083 & 2.060 & 30 & \\
Dimethylsulfoxide & 2.175 & 1.890 & 26 & \\
Propan-1-ol & 1.379 & 0.930 & 26 & Not used \\
Propan-2-ol & 1.143 & 0.928 & 26 & \\
tert-Butanol & 0.772 & 0.648 & 26 & \\
Methanol & 1.827 & 1.840 & 26 & \\
95\% methanol & 1.614 & 1.761 & 26 & \\
90\% methanol & 1.633 & 1.689 & 26 & \\
$80 \%$ methanol & 1.364 & 1.489 & 26 & \\
70\% methanol & 1.187 & 1.350 & 26 & \\
60\% methanol & 1.013 & 1.104 & 26 & \\
50\% methanol & 0.836 & 0.791 & 26 & \\
40\% methanol & 0.677 & 0.508 & 26 & \\
$30 \%$ methanol & 0.490 & 0.333 & 26 & \\
20\% methanol & 0.346 & 0.193 & 26 & \\
10\% methanol & 0.185 & 0.096 & 26 & \\
& & & & \\
& & &
\end{tabular}

These 46 equations yielded the descriptors shown in Table 7 and $\log C_{\mathrm{w}}=-2.37$, with a standard deviation between calculated and observed dependent variables of $0.136 \mathrm{log}$ units. The calculated and observed values of $\log P$ are in Table 8 . For the 22 used values, $\mathrm{AE}=$ $0.018, \mathrm{AAE}=0.117$ and $\mathrm{SD}=0.140 \log$ units.

In the case of $\mathrm{Co}(\mathrm{acac})_{3}$, solubilities are known in water $\left(\log C_{\mathrm{w}}=-2.41\right),{ }^{29}$ dimethylformamide, ${ }^{29}$ dodecane, ${ }^{27}$ various ethanol-water mixtures ${ }^{28}$ and alkoxyethanols. ${ }^{35}$ Alousy and Burgess. $^{26}$ have listed partition coefficients into methanolwater mixtures and into a large number of pure solvents. The solubilities were converted into $\log P$ values, and we were able to use 33 such values. We also had 33 of the corresponding $\log K_{\mathrm{s}}$ values, and two equations in $\log K_{\mathrm{w}}$ giving a total of 68 simultaneous equations. These were solved to yield the descriptors in Table 7 with an SD between the 68 calculated and observed values of $0.205 \mathrm{log}$ units. The observed and calculated values of $\log P$ are in Table 9 . For the 33 calculated and observed values that we used, $\mathrm{AE}=0.006, \mathrm{AAE}=0.136$ and $\mathrm{SD}=0.158 \log$ units.

The determined descriptors for the complexes of $\mathrm{Cr}, \mathrm{Fe}$ and Co, Table 7, do not very greatly between the three. All the complexes are quite polarizable, with $S$ ranging from 1.67 to 2.25 , as evidenced also by their dipole moments that vary from 0.95 to $1.10 .^{36}$ There is little variation in hydrogen bond basicity, and all the complexes have $A$ as zero. It might have been expected that a concentrated positive charge in the middle of the molecule would induce some hydrogen bond acidity for the $-\mathrm{CH}=$ hydrogen atom, but there is no doubt that $A=0$.

There are limited data for other $\mathrm{M}(\mathrm{acac})_{3}$ complexes, but only in a few cases are there enough to attempt to deduce descriptors. Even then, without a knowledge of $E$ and $V$, little can be done. Values of $V$ can be calculated exactly as for 
Table 9 Calculated and observed values of water-solvent partition coefficients, as $\log P$, for $\mathrm{Co}(\mathrm{acac})_{3}$

\begin{tabular}{|c|c|c|c|c|}
\hline Solvent & $\log P$ (calc) & $\log P$ (obs) & Ref. & \\
\hline Decane & -1.004 & -0.84 & 26 & \\
\hline Dodecane & -1.115 & -1.090 & 27 & \\
\hline Tetrachloromethane & 0.801 & 1.556 & 26 & Not used \\
\hline Dimethylformamide & 1.233 & 1.282 & 29 & \\
\hline Dimethylsulfoxide & 1.427 & 1.156 & 26 & \\
\hline Propan-1-ol & 0.849 & 0.280 & 26 & Not used \\
\hline Propan-2-ol & 0.593 & 0.280 & 26 & Not used \\
\hline Butan-1-ol & 0.672 & 0.928 & 26 & \\
\hline Hexan-1-ol & 0.689 & 0.948 & 26 & \\
\hline Octan-1-ol & 0.504 & 0.543 & 26 & \\
\hline Decan-1-ol & 0.510 & 0.367 & 26 & \\
\hline 2-Ethoxyethanol & 1.106 & 0.910 & 35 & \\
\hline 2-Butoxyethanol & 0.924 & 0.690 & 35 & \\
\hline Methanol & 1.348 & 1.346 & 26 & \\
\hline 95\% methanol & 1.109 & 1.240 & 26 & \\
\hline $90 \%$ methanol & 1.048 & 1.210 & 26 & \\
\hline $80 \%$ methanol & 0.916 & 1.190 & 26 & \\
\hline $70 \%$ methanol & 0.796 & 1.000 & 26 & \\
\hline $60 \%$ methanol & 0.691 & 0.808 & 26 & \\
\hline $50 \%$ methanol & 0.586 & 0.664 & 26 & \\
\hline $40 \%$ methanol & 0.497 & 0.420 & 26 & \\
\hline $30 \%$ methanol & 0.367 & 0.221 & 26 & \\
\hline $20 \%$ methanol & 0.278 & 0.140 & 26 & \\
\hline $10 \%$ methanol & 0.158 & 0.065 & 26 & \\
\hline Ethanol & 1.129 & 1.051 & 28 & \\
\hline $96 \%$ ethanol & 1.091 & 0.932 & 28 & \\
\hline $95 \%$ ethanol & 1.084 & 0.999 & 28 & \\
\hline $90 \%$ ethanol & 1.039 & 1.195 & 28 & \\
\hline $80 \%$ ethanol & 1.057 & 1.201 & 28 & \\
\hline $70 \%$ ethanol & 0.944 & 1.027 & 28 & \\
\hline $60 \%$ ethanol & 0.894 & 0.832 & 28 & \\
\hline $50 \%$ ethanol & 0.796 & 0.642 & 28 & \\
\hline $40 \%$ ethanol & 0.698 & 0.472 & 28 & \\
\hline $30 \%$ ethanol & 0.513 & 0.325 & 28 & \\
\hline $20 \%$ ethanol & 0.289 & 0.201 & 28 & \\
\hline $10 \%$ ethanol & 0.087 & 0.093 & 28 & \\
\hline
\end{tabular}

$\mathrm{Fe}(\mathrm{acac})_{3}$ with the atomic increments for $\mathrm{M}^{3+}$ atoms as shown in Table $2,{ }^{21}$ but without any experimental values of molar refraction, $E$ cannot be determined. However, $E$ does not seem to alter very much with the nature of the $\mathrm{M}^{3+}$ atom, and in the case of the $\mathrm{Cr}$, Fe and Co complexes, values of the obtained descriptors vary only slightly with change in the taken value of $E$. We therefore took $E$ as 2.48, the average of the $\mathrm{Cr}$, Fe and Co complexes,

Imura and $\mathrm{N}$. Suzuki ${ }^{37}$ have determined $\log P$ values for $\mathrm{V}(\mathrm{acac})_{3}$, and there is just enough information to obtain the descriptors given in Table 7. There is a little more data for the $\mathrm{M}(\mathrm{acac})_{3}$ complexes of yttrium, samarium, lanthanum and neodymium $^{38}$ and these yield the descriptors in Table 7 . The descriptors $S, B, L$ and $\log K_{\mathrm{w}}$ for these extra five complexes fall into the same pattern as shown by the $\mathrm{Cr}, \mathrm{Fe}$ and Co complexes. All four descriptors alter regularly with increase in the complex molecular weight, MW, over the eight complexes. The $B$ descriptor varies the most regularly, see eqn (11). This equation might be useful in the assignment of descriptors to other $\mathrm{M}(\mathrm{acac})_{3}$ complexes.

$$
\begin{gathered}
B=-0.904+0.00750 \mathrm{MW} \quad N=8, \mathrm{SD}=0.087, \\
R^{2}=0.937, F=89.72
\end{gathered}
$$

Table 10 Values of $\log P_{\text {oct }}$ for acetylacetonate complexes and some organic compounds

\begin{tabular}{lc}
\hline Compound & $\log P_{\text {oct }}$ \\
\hline $\mathrm{Cr}(\mathrm{acac})_{3}$ & 2.26 \\
$\mathrm{Fe}(\mathrm{acac})_{3}$ & 1.81 \\
$\mathrm{Co}(\mathrm{acac})_{3}$ & 1.36 \\
$\mathrm{~V}(\mathrm{acac})_{3}$ & 2.07 \\
$\mathrm{Y}(\mathrm{acac})_{3}$ & 0.47 \\
$\mathrm{Sm}(\mathrm{acac})_{3}$ & -0.96 \\
$\mathrm{La}(\mathrm{acac})_{3}$ & -1.06 \\
$\mathrm{Nd}(\mathrm{acac})_{3}$ & -1.05 \\
& \\
Glycerol tributanoate & 3.60 \\
Dibutyl adipate & 3.88 \\
Diheptyl ether & 6.42 \\
Pentadecane & 8.56
\end{tabular}

By comparison to organic compounds, there have been comparatively few studies on physicochemical properties of inorganic complexes. Analysis of solubilities has provided estimates of the solubility parameter of complexes, ${ }^{27,34,39}$ but the various predictive methods that have been so useful for organic compounds ${ }^{1-5}$ have not been applied to inorganic complexes. Now that we have descriptors for the three complexes, Table 7 , these can be used to predict $\log P$ values from the gas phase and from water to a very large number of both dry and wet solvents, as well as to several ionic liquids. We can illustrate this by the calculation of the water to wet octanol partition coefficient, as $\log P_{\text {oct }}$, commonly used as a measure of hydrophobicity. It is a simple matter to combine the descriptors in Table 7 with the equation coefficients given in Table 5 to yield the values given in Table 10. Our calculated $\log P_{\text {oct }}$ values vary regularly with complex molecular weight, from the somewhat hydrophobic $\mathrm{Cr}(\mathrm{acac})_{3}$ to the decidedly hydrophilic $\mathrm{Sm}$, La and Nd complexes, as shown in eqn (12) and by Fig. 3.

$$
\begin{gathered}
\log P_{\text {oct }}=13.989-0.0345 \mathrm{MW} \quad N=8, \mathrm{SD}=0.230, \\
R^{2}=0.979, F=247.2
\end{gathered}
$$

The quite good statistics of eqn (12) suggest that our assignment of $E=2.48$ for five of the complexes is at least reasonable.

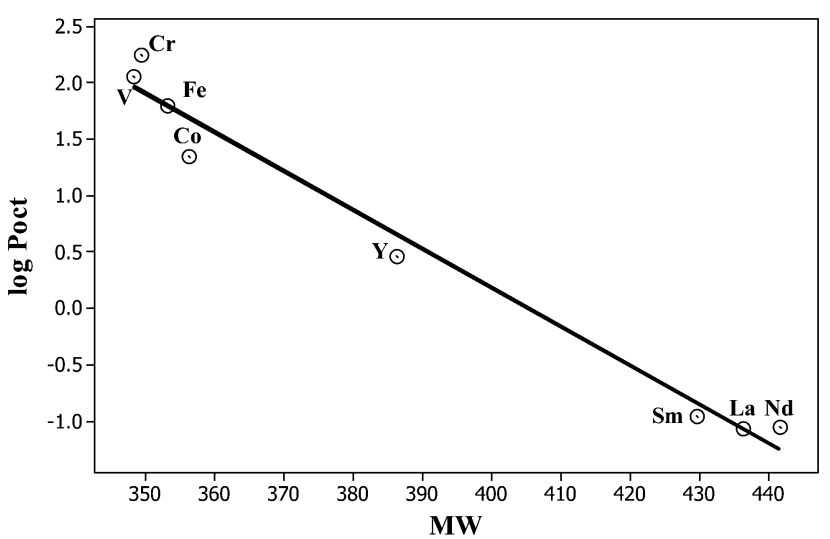

Fig. 3 A plot of calculated values of the water-octanol partition coefficient, as $\log P_{\text {oct, }}$ for the eight $\mathrm{M}(\mathrm{acac})_{3}$ complexes against the complex molecular weight. 
We can compare the values of $\log P_{\text {oct }}$ for the complexes with those for organic compounds with around 15 carbon atoms. This indicates that all the $\mathbf{M}(\mathrm{acac})_{3}$ complexes are much less hydrophobic than even glycerol tributanoate, which also has six oxygen atoms. Indeed, several of the complexes are hydrophilic.

\section{Conclusions}

We have shown that it is possible to employ the same methodology used to obtain Abraham descriptors for organic compounds to obtain Abraham descriptors for inorganic complexes. Then the various equations we have constructed for organic compounds can be used to predict a very large range of physicochemical properties for inorganic complexes. We have already shown ${ }^{40}$ that the methods used here can be extended to obtain descriptors for electrolytes and there is no fundamental reason why our extended method cannot be used to obtain descriptors for charged inorganic complexes (electrolytes) as well as for inorganic complexes that are nonelectrolytes, The main difficulty in obtaining descriptors for the inorganic complexes is in the estimation of the $E$-descriptor. In the present work we have determined the $E$-descriptor from our experimentally determined molar refractions for the tris(acetylacetonato)chromium(III), tris(acetylacetonato)iron(III) and tris(acetylacetonato)cobalt(III) complexes. This is a time-consuming procedure and at the moment is a limiting factor on the determination of the Abraham descriptors.

\section{Conflicts of interest}

There are no conflicts to declare.

\section{References}

1 BioLoom, BioByte Corp, 201 W. 4th Street, \#204 Claremont, CA 91711-4707, USA.

2 EPI Suite TM (2000-2012).

3 Chemsketch. ACD Advanced Chemistry Development, 110 Yonge Street, 14th Floor, Toronto, Ontario, M5C 1T4, Canada.

4 Absolv data base (2011), ADME Suite 5.0, Advanced Chemistry Development, 110 Yonge Street, 14th Floor, Toronto, Ontario, M5C 1T4, Canada.

5 SPARC http://archemcalc.com/sparc.

6 M. H. Abraham, Chem. Soc. Rev., 1993, 22, 73-83.

7 M. H. Abraham, A. Ibrahim and A. M. Zissimos, J. Chromatogr. A, 2004, 1037, 29-47.

8 C. F. Poole, S. N. Atapattu, S. K. Poole and A. K. Bell, Anal. Chim. Acta, 2009, 652, 32-53.

9 C. F. Poole, T. C. Ariyasena and N. Lenca, J. Chromatogr. A, 2013, 1317, 85-104.

10 E. D. Clarke and L. Mallon, The Determination of Abraham Descriptors and their Application to Crop Protection Research, in Modern Methods in Crop Protection Research, ed. P. Jeschke, W. Krämer, U. Schirmer and M. Witschel, Wiley-VCH Verlag GmbH \& Co., 2012.

11 M. H. Abraham, R. E. Smith, R. Luchtefeld, A. J. Boorem, R. Luo and W. E. Acree, Jr, J. Pharm. Sci., 2010, 99, 1500-1515.
12 M. Brumfield, W. E. Acree Jr. and M. H. Abraham, Phys. Chem. Liq., 2015, 53, 25-37.

13 M. Brumfield, A. Wadawadigi, N. Kuprasertkul, S. Mehta, W. E. Acree Jr. and M. H. Abraham, Phys. Chem. Liq., 2015, 53, 10-24.

14 M. H. Abraham, J. Gil-Lostes, W. E. Acree, Jr., J. E. ComettoMuñiz and W. S. Cain, J. Environ. Monit., 2008, 10, 435-442.

15 M. H. Abraham and W. E. Acree, Jr., New J. Chem., 2012, 36, 626-631.

16 M. H. Abraham and W. E. Acree, Jr., J. Mol. Liq., 2017, 232, 325-331.

17 A. Fucaloro, A. Zanella, S. Widjaja and J. Widjaja, J. Solution Chem., 2005, 34, 1357.

18 A. F. Fucaloro, J. Solution Chem., 2002, 31, 601-605.

19 S. Endo, N. Watanabe, N. Ulrich, G. Bronner and K.-U. Goss, UFZ-LSER database v 2.1 [Internet], Leipzig, Germany, Helmholtz Centre for Environmental Research-UFZ. 2015, accessed on 04.08.2016, available from https://www.ufz.de/ index.php?en $=31698 \&$ contentonly $=1 \& \mathrm{~m}=0$ \&lserd_data[mvc $]=$ Public/start.

20 M. H. Abraham and J. C. McGowan, Chromatographia, 1987, 23, 243-246.

21 Y. H. Zhao, M. H. Abraham and A. M. Zissimos, J. Chem. Inf. Comput. Sci., 2003, 43, 1848-1854.

22 D. Tran, J. P. Hunt and S. Wherland, Inorg. Chem., 1992, 31, 2460-2464.

23 G. J. Kruger and E. C. Reynhardt, Acta Crystallogr., 1974, B30, 822-824.

24 B. Morosin, Acta Crystallogr., 1965, 19, 131-137.

25 R. B. Roof, Acta Crystallogr., 1956, 9, 781-786.

26 A. Alousy and J. Burgess, Polyhedron, 1992, 11, 531-539.

27 H. Watari, H. Ochima and N. Suzuki, Quant. Struct.-Act. Relat., 1984, 3, 17-22.

28 V. A. Fedorov, N. V. Vologdin, N. P. Samsonova, P. V. Fabinskii and A. V. Fedorova, Russ. J. Inorg. Chem., 2011, 56, 141-144.

29 N. V. Vologdin, P. V. Fabinskii and V. A. Fedorov, Russ. J. Phys. Chem., 2015, 89, 65-68.

30 S. Brandani, V. Brandani and G. Di Giacomo, Gazz. Chim. Ital., 1994, 124, 295-297.

31 M. H. Abraham and W. E. Acree, Jr., J. Solution Chem., 2016, 45, 861-874.

32 I. A. Sedov, M. A. Stolov, E. Hart, D. Grover, H. Zettl, V. Koshevarova, C. Dai, S. Zhang, W. E. Acree, Jr. and M. H. Abraham, J. Mol. Liq., 2015, 209, 196-202.

33 I. A. Sedov, M. A. Stolov, E. Hart, D. Grover, H. Zettl, V. Koshevarova, W. E. Acree, Jr. and M. H. Abraham, J. Mol. Liq., 2015, 208, 63-70.

34 H. Koshimura, J. Inorg. Nucl. Chem., 1978, 40, 865-874.

35 Y. Yoshimura, Can. J. Chem., 1989, 67, 2108-2115.

36 V. Singh and R. Sahai, J. Macromol. Sci., Chem., 1985, A22, 33-42.

37 H. Imura and N. Suzuki, Bull. Chem. Soc. Jpn., 1986, 59, 2779-2783.

38 O. Erämetsä and S. Hämälä, Suom. Kemistil. B, 1958, 31, 204-207. 39 J. W. Mitchell and C. V. Banks, J. Inorg. Nucl. Chem., 1969, 31, 2105-2115.

40 M. H. Abraham and W. E. Acree, Jr., J. Org. Chem., 2010, 75, 1006-1015. 